\title{
Pediatric nonalcoholic fatty liver disease - a changing diagnostic paradigm
}

\author{
Laura Mihaela Trandafir ${ }^{1)}$, Otilia Elena FrasinariU ${ }^{1)}$, Maria Magdalena LeON-CONSTANTIN ${ }^{2}$,

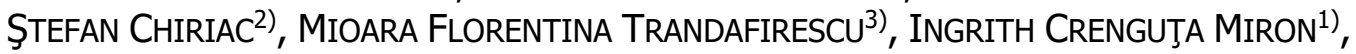 \\ ALINA COSTINA LUCA ${ }^{1)}$, ALIN CONSTANTIN IORDACHE ${ }^{4}$, ELENA COJOCARU ${ }^{5)}$
}

\author{
1) Department of Mother and Child Medicine - Pediatrics, Grigore T. Popa University of Medicine and Pharmacy, Iaşi, Romania \\ 2) First Medical Department, Grigore T. Popa University of Medicine and Pharmacy, Iaşi, Romania \\ 3) Department of Morphofunctional Sciences I - Histology, Grigore T. Popa University of Medicine and Pharmacy, Iaşi, Romania \\ ${ }^{4)}$ Second Surgery Department - Neurosurgery, Grigore T. Popa University of Medicine and Pharmacy, Iaşi, Romania \\ ${ }^{5)}$ Department of Morphofunctional Sciences I - Pathology, Grigore T. Popa University of Medicine and Pharmacy, Iaşi, Romania
}

\begin{abstract}
Worldwide, nonalcoholic fatty liver disease (NAFLD) has emerged as the leading cause of chronic liver disease in children and adolescents, but also as a real public health issue. Over the last decades, the increase in the rates of obesity and overweight in children has led to the increase in the worldwide prevalence of pediatric NAFLD. Detection of a hyperechoic appearance of the liver at ultrasounds or elevated levels of transaminases, identified during a routine control in children, suggests NAFLD. The disorder can be diagnosed with either non-invasive strategies or through liver biopsy, which further allows the identification of specific histological aspects, distinct from those found in adults. Since NAFLD is a clinically heterogeneous disease, there is an imperative need to identify noninvasive biomarkers and screening techniques for early diagnosis in children, in order to prevent metabolic and cardiovascular complications later in adulthood. This review emphasizes the main diagnosis tools in pediatric NAFLD, a systemic disorder with multifactorial pathogenesis and varying clinical manifestations.
\end{abstract}

Keywords: fatty liver disease, hepatic steatosis, steatohepatitis, fibrosis, scoring systems, non-invasive biomarkers.

\section{ㅁ Introduction}

The increased prevalence of obesity among children has led to a rise of its comorbidities, such as nonalcoholic fatty liver disease (NAFLD) at early ages. NAFLD is responsible for a wide range of liver related issues, such as simple steatosis, nonalcoholic steatohepatitis (NASH), advanced fibrosis, and cirrhosis. At the present time, NAFLD is the most significant and prevalent form of liver disease both in adults and children. For adult patients, terminal liver disease caused by NAFLD represents the primary cause of liver transplantation [1-3]. The onset of NAFLD in childhood leads to the development of advanced liver disease in young adults and the early onset of comorbidities, such as metabolic syndrome (MS) and cardiovascular disease. Some authors consider NAFLD the liver manifestation of MS [1,4]. Given the fact that cardiovascular disease is the main cause of death in adult patients suffering of NAFLD, a pivotal step is to diagnose NAFLD early in childhood and adolescence in order to properly ensure adequate therapeutic interventions.

Due to its direct association with insulin resistance and obesity, NAFLD it is a real public health problem since childhood. Typically, pediatric NAFLD is diagnosed especially in males and around the age of 11-13 years. Steatohepatitis is usually reported in the prepubertal age group, obesity, diabetes, acanthosis nigricans, and polycystic ovary syndrome being clinical markers of insulin resistance [1].
As there are no precise or sensitive noninvasive makers of NAFLD, it is fairly difficult to pinpoint its exact incidence. In patients in whom the diagnosis of NAFLD was established using non-invasive tests [alanine aminotransferase (ALT) values and liver ultrasound (US)], the percentage registered in the pediatric age NAFLD was no more than $7.6 \%$, while among the obese children group it rose up to $34 \%[2,5]$. Studies that established this diagnosis using histopathological (HP) examination showed a worldwide prevalence of NAFLD that ranged from $4.2 \%$ to $9.6 \%$, as well as a prevalence of $38 \%$ in obese children and adolescents $[2,6]$. NAFLD is underdiagnosed in children, as there are currently no evidencebased solid recommendations for screening in the pediatric population. Novel biomarkers as well as therapeutic agents are required in order to avert the possible longstanding consequences of NAFLD and its associated complications.

\section{ㅁ Etiopathogeny}

NAFLD in pediatric-aged patients is undoubtedly linked with several metabolic risk factors, such as insulin resistance, dyslipidemia, cardiovascular disease and, most notably, visceral adiposity $[7,8]$. From the etiopathogenic point of view, the development and progression of NAFLD are secondary to complex interactions between metabolic, genetic, epigenetic, and environmental mechanisms [1, 2 , 9]. Now, the "multiple-hit model" theory is widely

This is an open-access article distributed under the terms of a Creative Commons Attribution-NonCommercial-ShareAlike 4.0 International Public License, which permits unrestricted use, adaptation, distribution and reproduction in any medium, non-commercially, provided the new creations are licensed under identical terms as the original work and the original work is properly cited. 
accepted in the pathogenesis of NAFLD [10]. The starting point for the development of NAFLD is the excessive accumulation of lipids in the hepatocyte, lipotoxicity, systemic inflammation, and oxidative stress. Subsequently, steatosis stimulates liver tissue through the secretion of cytokines which contributes to fibrotic remodeling of the liver and development of liver cirrhosis and hepatocellular carcinoma [10-12].

Moreover, according to the theory of metabolic programming of chronic diseases, the stress factors that act in intrauterine and perinatal period increase the risk of cardiometabolic diseases and NAFLD. Thus, maternal nutrition influences the child's risk of developing NAFLD by inducing persistent changes in liver metabolism, mitochondrial function, and postnatal gut microbiota [2].

\section{Histopathological features}

Steatosis or fatty liver is a nonspecific condition that occurs through an accumulation of neutral lipids in liver parenchymal cells.

Macroscopically, the liver with steatosis is enlarged, soft, golden-yellow with rounded edges. From microscopic viewpoint, steatosis may show a macrovesicular pattern with a single large lipid droplet which pushes the nucleus into the periphery or microvesicular pattern with multiple small droplets around the nucleus centrally placed. These stages are reversible, since the removal of the cause leads to the morpho-functional restoration of the cell. When in hepatocytes with macrovesicular steatosis, the plasma membranes of adjacent cells are destroyed, lipid cysts are formed; this are irreversible lesions [13]. Generally, the injury begins in the centrilobular region (zone 3 ) and affect progressively 2 and 1 zones [14].

Sometimes microvesicular steatosis may be linked to major damage of the mitochondrial beta-oxidation of fatty acids. In this case, electron microscopy may reveal megamitochondria in the affected cells [11]. Generally, a pure microvesicular pattern is unusual and may appear in Reye syndrome, in the presence of mitochondrial disorders or in drug-induced maladies [15]. Significant microvesicular steatosis seems to be related with liver failure, pancreatitis, hypoglycemia, azotemia [16].

The persistence of various factors inducing steatosis determines in children and adolescents' NASH, which is associated with fibrosis and progressive disease. HP features of steatohepatitis are hepatocyte damage starting of ballooning degeneration, Mallory-Denk bodies (MDBs) and/or pericellular fibrosis, associated or not with steatosis, necrosis (Figures 1 and 2) or apoptosis of cells [13, 14].

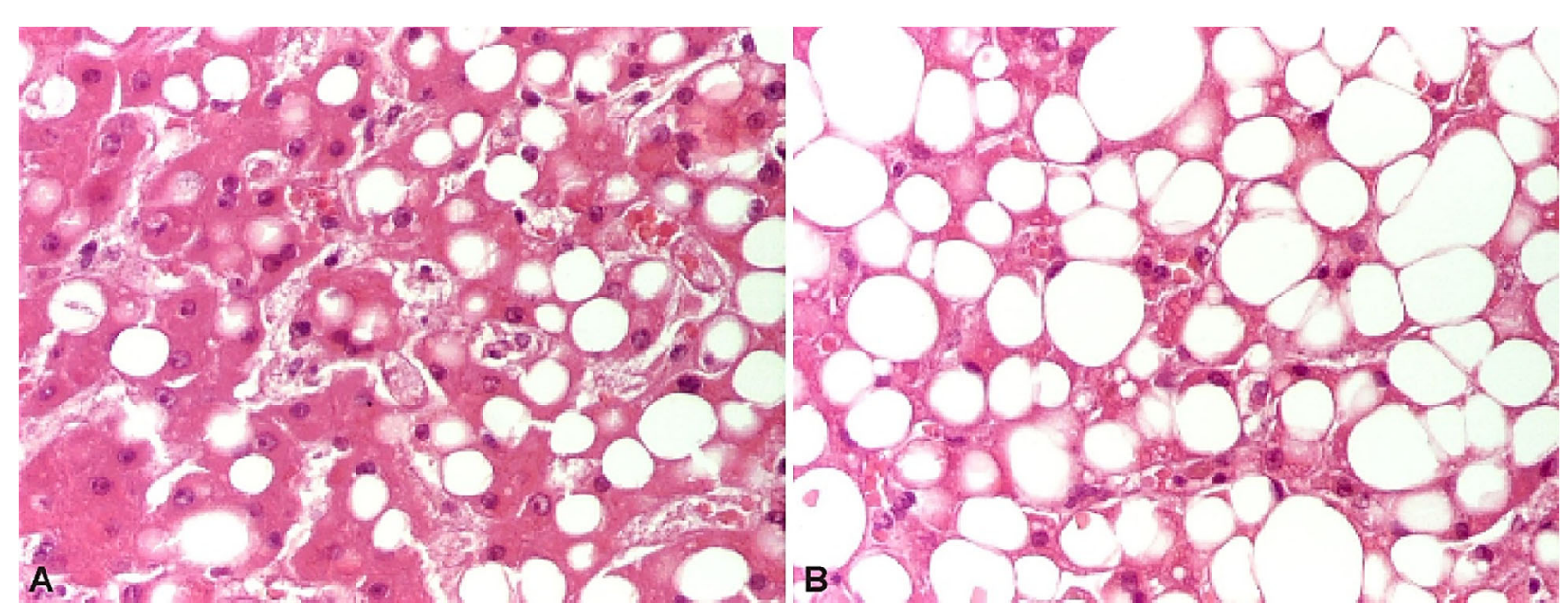

Figure 1 - Steatohepatitis displaying ballooning degeneration and steatosis. HE staining: $(A$ and B) $\times 200 . H E$ : Hematoxylin-Eosin.

In ballooning degeneration, which is the main feature of hepatic injury, the hepatocytes are enlarged with clear cytoplasm and well-defined cell membranes. It is associated in prognostic studies with severe impairment and an increased incidence of cirrhosis in adults. The appearance of ballooning degeneration could be the consequence of the accumulation of intracellular fluid because of cytoskeletal dysfunction. In addition, other characteristic lesions may be noted: MDBs, mega mitochondria, glycogenated nuclei and iron deposits. MDBs are made of aggregation of cytoskeleton filaments and resemble eosinophilic intracytoplasmic material disposed near to the nucleus. Inflammatory cells in steatohepatitis may consist of neutrophils and very often lymphocytes, histiocytes and Kupffer cells disposed in the lobules or within portal tracts, fewer than in chronic viral hepatitis. In children, the inflammation is more common in portal area and it is considered a marker of severity of the adults' disease [13-15].

In NAFLD, fibrosis begins as deposition of perisinusoidal or pericellular collagen fibers in the centrilobular area and spreads outer into the lobules. In advanced stages, there may be bridging fibrosis connecting neighboring central veins or central veins and portal tracts [16].

Compared histological studies regarding steatohepatitis in adult and childhood reported some differences [17].

In children steatosis initiates around the portal tracts (zone 1) and more significant portal inflammation and portal fibrosis is detected compared to adults (Figure 3). Moreover, features such as ballooning or lobular inflammation are less likely to be identified in children compared to adults. Special stainings are useful in studying the lesions [18]. Thus, Masson's trichrome staining is useful when assessing the degree of fibrosis while the 
reticulin stain can display any growth in pericellular reticulin fibers. A differential diagnosis should be made with drug-induced steatohepatitis, alcoholic steatohepatitis and jejunoileal bypass $[19,20]$.

In children and adolescents, two types of steatohepatitis have been described: type 1 or the adult-type steatohepatitis, with primarily involvement of zone 3 (centrilobular) of the hepatic lobule, and type 2 steatohepatitis, characterized by inflammation and fibrosis, panacinar steatosis and reduced ballooning degeneration (Figure 4), and MDBs predominant in the zone 1 (periportal) of the hepatic lobule [18, 21-23]. Generally, in type 2 steatohepatitis, the fibrosis is more prominent. Epidemiological studies show that type 2 steatohepatitis is more frequent in younger children, obese boys, and non-White origin, while adolescents tend to develop type 1 or adult type features, most likely because of hormonal changes related to puberty [21, 24]. For this reason, grading systems for NAFLD have been suggested, considering the proportion of hepatocytes with macrovesicular steatosis, hepatocyte damage as ballooning degeneration, lobular inflammation, and fibrosis $[18,23,25]$. Three scoring systems are more commonly used: the Brunt system (Table 1) [26], the NASH Clinical Research Network (CRN) system [27] and the steatosis-activity-fibrosis (SAF) system [28].
Table 1 - Grading and staging of histopathological lesions (modified after Brunt et al., 1999) [26]

\begin{tabular}{|c|c|}
\hline \multicolumn{2}{|c|}{ Steatosis grading } \\
\hline \multicolumn{2}{|c|}{ Grade 0: absence of macrovesicular steatosis. } \\
\hline \multicolumn{2}{|c|}{ Grade 1: $<33 \%$ of affected hepatocytes. } \\
\hline \multicolumn{2}{|c|}{ Grade 2: $33-66 \%$ of affected hepatocyte. } \\
\hline \multicolumn{2}{|c|}{ Grade 3: $>66 \%$ of affected hepatocytes. } \\
\hline \multicolumn{2}{|c|}{ Steatohepatitis grading } \\
\hline $\begin{array}{l}\text { Grade } 1 \\
\text { mild }\end{array}$ & $\begin{array}{l}\text { Macrovesicular steatosis involving up to } 66 \% \\
\text { of the lobules, occasional hepatocyte ballooning } \\
\text { (predominantly in zone 3), acute lobular } \\
\text { inflammation with the presence of PMNs; } \\
\text { portal inflammation - absent or slight. }\end{array}$ \\
\hline $\begin{array}{l}\text { Grade 2, } \\
\text { moderate }\end{array}$ & $\begin{array}{l}\text { Steatosis of any grade, degenerative ballooning } \\
\text { present in zone } 3 \text {, lobular inflammation, mild or } \\
\text { moderate perisinusoidal fibrosis, portal } \\
\text { inflammation. }\end{array}$ \\
\hline $\begin{array}{l}\text { Grade 3, } \\
\text { severe }\end{array}$ & $\begin{array}{l}\text { Panacinar steatosis, marked hepatocyte ballooning, } \\
\text { acute lobular inflammation with PMNs around } \\
\text { ballooned hepatocytes, portal inflammation. }\end{array}$ \\
\hline \multicolumn{2}{|c|}{ Fibrosis staging } \\
\hline Stage 1 & $\begin{array}{l}\text { Pericellular/perisinusoidal fibrosis in zone } 3 \text {, } \\
\text { focal or extensive. }\end{array}$ \\
\hline Stage 2 & $\begin{array}{l}\text { Pericellular/perisinusoidal fibrosis in zone } 3+ \\
\text { focal or extensive periportal fibrosis. }\end{array}$ \\
\hline Stage 3 & $\begin{array}{l}\text { Pericellular/perisinusoidal fibrosis in zone } 3+ \\
\text { portal fibrosis + bridging fibrosis. }\end{array}$ \\
\hline Stage 4 & Cirrhosis. \\
\hline
\end{tabular}

PMN: Polymorphonuclears.
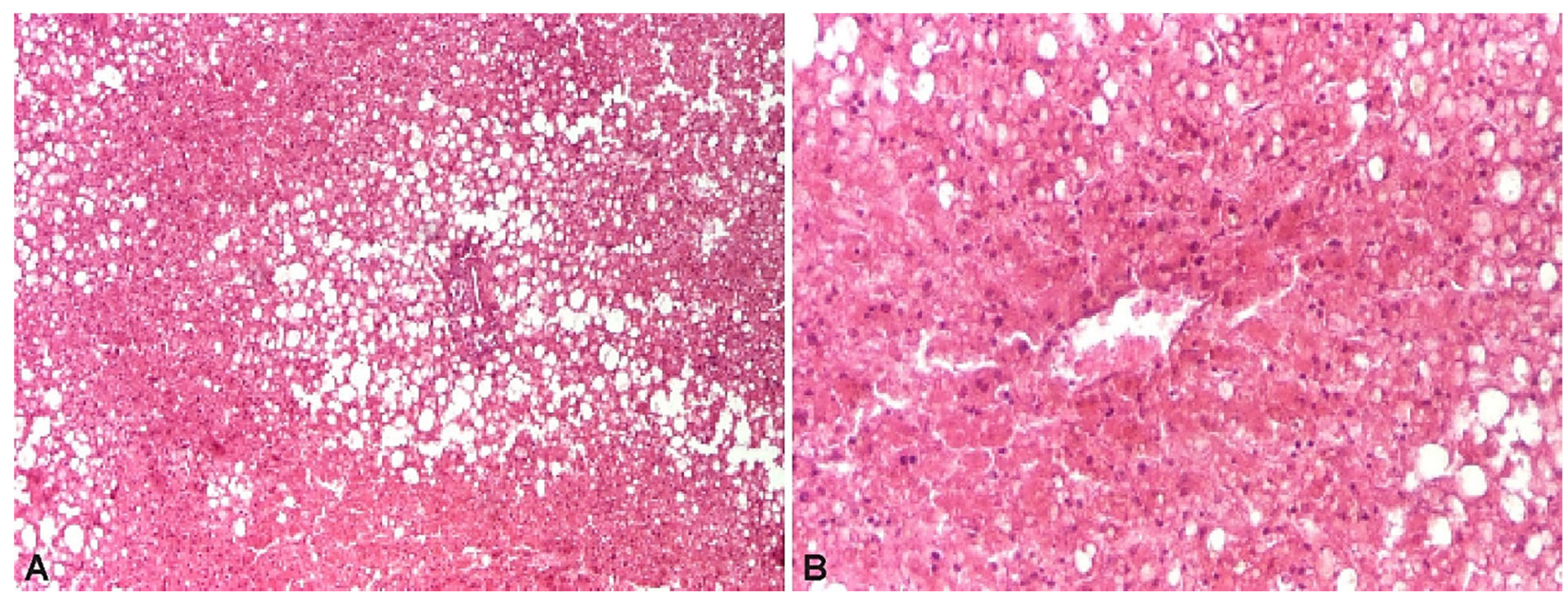

Figure 2 - Steatohepatitis showing hepatocytes necrosis. HE staining: $(A) \times 40 ;(B) \times 100$. HE: Hematoxylin-Eosin.
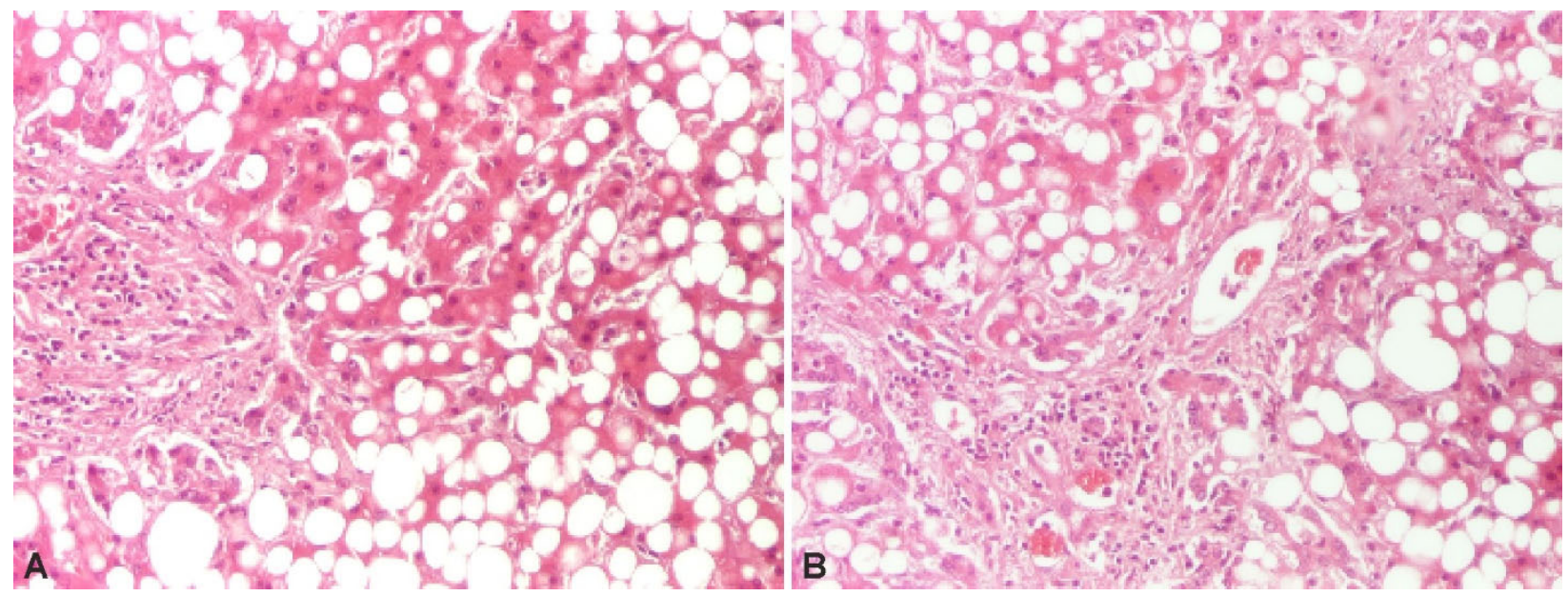

Figure 3 - Steatohepatitis showing macrovesicular steatosis. HE staining: (A and B) $\times 100$. HE: Hematoxylin-Eosin. 


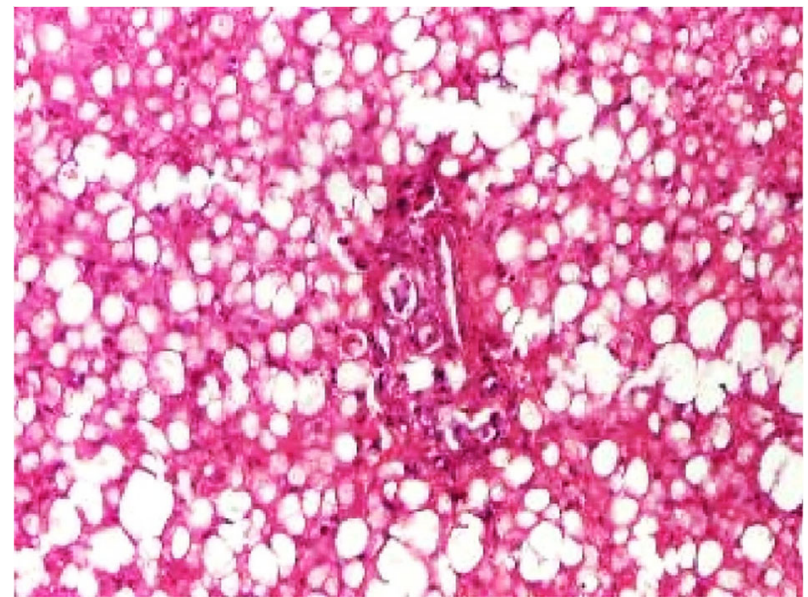

Figure 4 - Type 2 (pediatric type) NAFLD with a periportal distribution. $H E$ staining, $\times 100 . H E$ : Hematoxylin-Eosin; NAFLD: Nonalcoholic fatty liver disease.

\section{ㅁ Diagnosis}

The diagnosis of NAFLD is established in the absence of other liver diseases (for instance inborn errors of fatty acid metabolism, peroxisomal disorders or lysosomal storage disorders) or simply by random diagnosis. Unfortunately, a significant number of patients remain undiagnosed [29]. Frequently, unexplained persistent elevation of transaminases and/or US-diagnosed steatosis establishes the diagnostic of NAFLD in obese children. The high levels of transaminases values are associated with an increased risk of severe liver disease. In adults, up to $30-60 \%$ of patients with histologically proven NASH present normal ALT values. This further implies that LB is the most accurate method to make the clear distinction between NASH and hepatic steatosis [30]. Significant steatosis may also be detected by imaging studies, but their sensitivity decreases prominently when steatosis is $<50 \%$ [31].

LB is considered to be the best solution for correctly identifying NASH and consequently establishing the severity of the disease. Simultaneously, it can also make a clear difference between simple steatosis and steatohepatitis. Another plus is that it provides valuable information about the changes in liver architecture, as well as the severity of inflammatory activity and fibrosis [29, 32]. In addition, it is useful in excluding other conditions associated with steatosis, such as hepatitis C, Wilson's disease, autoimmune hepatitis, and other liver metabolic diseases. Histology allows the monitoring of the disease progression and response to therapy, knowing that transaminase levels may vary or even normalize, regardless of whether fibrosis progresses or stagnates [33, 34].

The decision to perform a LB in children, in order to confirm the diagnosis of NAFLD, must weigh the risks versus the importance of the information obtained and also the impact on management. A high risk for NASH could represent a biopsy indication in children in order to allow the grading of the disease. In the absence of strong evidence-based recommendations for biopsies in children, Robertson et al. proposes in 2007 several criteria: young age (less than 10 years old), a family record of severe registered NAFLD, the existence of hepatosplenomegaly on physical examination, and modified biochemical markers (such as marked/persistent elevated transaminases, insulin resistance, presence of nonspecific autoantibodies) [35]. However, the use of LB in the pediatric population is limited because of the method invasiveness and the risk of association with major complications, such as bleeding, which can occur in both adults and children [36].

Consequently, there is an urgent need to identify noninvasive biomarkers and screening techniques suitable for early diagnosis of NAFLD and NASH, as well as to monitor patients, especially as lifestyle changes and potentially future pharmacological compounds could represent treatment alternatives $[7,31]$.

\section{ㅁ Noninvasive markers}

NAFLD and NASH are multifactorial diseases and there is no established marker that could predict the clinical evolution or benefits of treatment. The progression from NAFLD to NASH involves a variety of hormonal, molecular and cellular changes. Multiple biomarkers have been developed to highlight the severity of liver disease (Table 2).

Table 2 - The main non-invasive markers studied in NAFLD

\begin{tabular}{|c|c|c|c|c|}
\hline & $\begin{array}{c}\text { Markers of } \\
\text { inflammation }\end{array}$ & $\begin{array}{c}\text { Markers of oxidative } \\
\text { stress }\end{array}$ & $\begin{array}{l}\text { Markers of } \\
\text { apoptosis }\end{array}$ & Markers of fibrosis \\
\hline $\begin{array}{l}\text { Routinely used } \\
\text { markers }\end{array}$ & $\begin{array}{c}\text { CRP } \uparrow \\
\text { Adiponectin } \downarrow \\
\text { Leptin } \uparrow \\
\text { Ferritin } \uparrow\end{array}$ & LDL oxidation $\uparrow$ & & $\begin{array}{l}\text { Nonspecific: } \\
\text { - AST/ALT ^; } \\
\text { - GGT; } \\
\text { - FibroTest; } \\
\text { - FIB-4 score: age, AST or ALT, platelets. } \\
\text { Specific: } \\
\text { - PNFI: age, WBC, triglycerides. }\end{array}$ \\
\hline $\begin{array}{l}\text { Markers used in } \\
\text { clinical trials }\end{array}$ & $\begin{array}{c}\text { TNF } \alpha \uparrow \\
\text { IL-6 } \uparrow \\
\text { RBP4 } \\
\text { Bacterial endotoxin } \uparrow \\
\text { Fetuin-A } \uparrow \\
\text { Resistin } \\
\text { Visfatin } \\
\text { PAl-1 }\end{array}$ & $\begin{array}{c}\text { Hepatic expression } \\
\text { of } 8-O H d G\end{array}$ & $\mathrm{CK} 18 \uparrow$ & $\begin{array}{l}\text { Nonspecific: } \\
\text { - HA; } \\
\text { - Laminin. } \\
\text { Specific: } \\
\text { - ELF panel: HA, TIMPs, PIIINP. }\end{array}$ \\
\hline
\end{tabular}

8-OHdG: 8-Hydroxy-2'-deoxyguanosine; ALT: Alanine aminotransferase; AST: Aspartate aminotransferase; CK18: Cytokeratin 18; CRP: C-reactive protein; ELF: Enhanced liver fibrosis; FIB-4: Fibrosis-4; GGT: Gamma-glutamyl transferase; HA: Hyaluronic acid; IL-6: Interleukin-6; LDL: Low-density lipoprotein; NAFLD: Nonalcoholic fatty liver disease; PAI-1: Plasminogen activation inhibitor-1; PIIINP: Procollagen III $N$-terminal peptide; PNFI: Pediatric NAFLD fibrosis index; RBP4: Retinol binding protein 4; TIMPs: Tissue inhibitors of metalloproteinases; TNF $\alpha$ : Tumor necrosis factor alpha; WBC: White blood cells. 
A variety of inflammatory markers are elevated in the serum of NASH patients: C-reactive protein, tumor necrosis factor-alpha, interleukin (IL)-6, and IL-8. The most important difference between simple steatosis and NASH is mainly represented by the absence of inflammatory infiltrate in the first one. NASH is mainly characterized by changes in glucose and lipid metabolism that include numerous adipokines. Among adipokines, adiponectin and chemerin have been investigated as non-invasive biomarkers for liver steatosis evaluation $[1,2,37]$.

A study performed by Flisiak-Jackiewicz \& Lebensztejn showed positive correlations between body mass index, aspartate aminotransferase (AST), ALT, triglycerides and gamma-glutamyl transferase with chemerin and significant negative correlations of these parameters with adiponectin $[1,38]$. Other adipokines, such as leptin, resistin, or visfatin, are associated with the severity of NAFLD and may be considered as potential indicators of the diseases not only in children, but also in adults $[1,39]$.

Hepatocyte death and extracellular matrix specific biochemical markers such as cytokeratin 18 (CK18) and hyaluronic acid (HA) are correlated with the stage of fibrosis [37]. The CK18 apoptosis marker shows elevated plasma levels in patients with NASH, thus indicating hepatocyte destruction by apoptosis and necrosis. Levels of CK18 underline a major correlation with the incidence of NASH but they should not be expected to make a difference between different levels of severity of NASH. The development of noninvasive biomarkers is still one of the most intensely exploited areas of current research. Thus, a massive amount of effort is being dedicated to messenger ribonucleic acid (mRNA) expression analysis, genetic profiling, proteomics, and metabolomics [40 42]. Moreover, genetic components involved in the development and progression of NASH are currently being investigated, which will hopefully lead to the implementation of adequate therapeutic intervention, as well as the identification of supplementary liver disease risk factors. Genetic factors contribute up to no less than $30-50 \%$ in the prevalence of many different diseases which include obesity, type 2 diabetes, cardiovascular disease or liver cirrhosis. One of the genes involved in this process is patatin-like phospholipase domain-containing protein 3 (PNPLA3) which mediates the triacylglycerol hydrolysis in adipocytes and hepatocytes [40].

\section{Non-invasive fibrosis evaluation scoring systems}

As previously stated, the LB limitations have incited the development of alternative non-invasive scoring systems, which are currently directed towards the assessment of hepatic fibrosis. Most of these tests, such as AST/ALT ratio, AST to platelet ratio index (APRI), NAFLD fibrosis score (NFS), Fibrosis-4 (FIB-4), were developed for adult patients. However, there is still controversy regarding their accuracy in the assessment of pediatric NAFLD. While several authors found that some of these scores reflected the presence of hepatic fibrosis with adequate accuracy [43, 44], others did not [45, 46]. Also, even though many of these scores have proven their utility in the prediction of fibrosis in pediatric patients with viral hepatitis, biliary atresia and cystic fibrosis, their role in the setting of NAFLD has not yet been firmly established [47]. Moreover, the North American Society for Pediatric Gastroenterology, Hepatology, and Nutrition (NASPGHAN) recommendations state that the evidence favoring the use of these scoring systems is not strong enough to justify their routine clinical use in the evaluation of patients with NAFLD (Table 3) [34].

Table 3 - The usefulness of hepatic fibrosis scoring systems in pediatric patients diagnosed with NAFLD

\begin{tabular}{|c|c|c|}
\hline $\begin{array}{c}\text { Hepatic } \\
\text { fibrosis score }\end{array}$ & $\begin{array}{c}\text { Parameters } \\
\text { used }\end{array}$ & $\begin{array}{l}\text { Accuracy in pediatric } \\
\text { patients }\end{array}$ \\
\hline $\begin{array}{l}\mathrm{AST} / \mathrm{ALT} \\
\text { ratio }\end{array}$ & AST, ALT & Very low $[6,9]$ \\
\hline APRI & AST, platelets & High [9] \\
\hline Forns index & $\begin{array}{c}\text { Total bilirubin, GGT, } \\
\alpha_{2} \text {-macroglobulin, } \\
\text { apolipoprotein A1, } \\
\text { haptoglobin. } \\
\end{array}$ & Moderate [9] \\
\hline $\begin{array}{l}\text { FIB-4 } \\
\text { score }\end{array}$ & $\begin{array}{l}\text { Age, AST, ALT, } \\
\text { platelets }\end{array}$ & $\begin{array}{l}\text { High accuracy in } \\
\text { differentiating significant } \\
\text { from mild fibrosis [9]. }\end{array}$ \\
\hline $\begin{array}{l}\text { ELF } \\
\text { test }\end{array}$ & $\begin{array}{l}\text { HA, PIIINP, } \\
\text { TIMP-1 }\end{array}$ & $\begin{array}{l}\text { Good accuracy for } \\
\text { differentiating significant } \\
\text { fibrosis (stage } 3 \text { ) from mild } \\
\text { or no fibrosis (AUROC=0.99, } \\
10.51 \text { cutoff) [4]. }\end{array}$ \\
\hline PNFI & $\begin{array}{l}\text { Age, waist } \\
\text { circumference, } \\
\text { triglyceride } \\
\text { level. }\end{array}$ & $\begin{array}{l}\text { Good accuracy for } \\
\text { differentiating hepatic } \\
\text { fibrosis from no fibrosis } \\
\text { (AUROC }=0.85,0.76 \\
\text { respectively) }[3,10] .\end{array}$ \\
\hline $\begin{array}{l}\text { PNFI + ELF } \\
\text { test }\end{array}$ & - & $\begin{array}{l}\text { Excellent accuracy for } \\
\text { the prediction of hepatic } \\
\text { fibrosis }(A \cup R O C=0.94)[3] .\end{array}$ \\
\hline
\end{tabular}

ALT: Alanine aminotransferase; APRI: AST to platelet ratio index; AST: Aspartate aminotransferase; AUROC: Area under the receiver operating characteristics curve; ELF: Enhanced liver fibrosis; FIB-4: Fibrosis-4; GGT: Gamma-glutamyl transferase; HA: Hyaluronic acid; NAFLD: Nonalcoholic fatty liver disease; PIIINP: Procollagen III N-terminal peptide; TIMP-1: Tissue inhibitor of metalloproteinase-1; PNFI: Pediatric NAFLD fibrosis index.

The AST/ALT ratio was one of the first fibrosis scoring system evaluated in pediatric patients. A study carried out in 2008 included 176 children evaluated by standard biochemical parameters and then by LB. Although AST/ALT ratio presented an area under the curve (AUC) of 0.74 for discriminating between bridging fibrosis and a lesser degree of fibrosis the authors concluded that the results were not satisfactory when compared to the superior accuracy of LB [45]. More recent results from Yang et al., who studied 77 pediatric patients diagnosed with NAFLD by LB, showed an even lower accuracy of AST/ALT ratio in predicting hepatic fibrosis $(A U C=0.53)$. However, the same authors found FIB-4 to be the most accurate marker for hepatic fibrosis, with an AUC of 0.81 , followed by Forns index, with an AUC of 0.73, and APRI, with an AUC of 0.70 [48].

In 2009, Nobili et al. assessed the utility of the enhanced liver fibrosis (ELF) test in the assessment of fibrosis in pediatric patients in a study comprising 112 patients with biopsy proven NAFLD. Although this score was designed and validated for the use in adult patients the authors found that a cutoff of 9.28 presented a sensitivity of $88 \%$ and a specificity of $81 \%$ for the identification of hepatic fibrosis. The disadvantage of this score was the requirement of expensive workup, 
including testing of parameters which were not readily available in clinical practice, such as HA, procollagen III $N$-terminal peptide (PIIINP), and tissue inhibitor of metalloproteinase-1 (TIMP-1) [49]. The introduction of the pediatric NAFLD fibrosis index (PNFI) by Nobili et al., in 2009, represented a step forward the improvement of non-invasive hepatic fibrosis assessment in children. Its advantages consisted in simplicity and cost-efficiency, as it was calculated using only the age, waist circumference, and triglyceride levels, thus providing clinicians with an adequate positive predictive value for hepatic fibrosis. A PNFI over 9 indicated with $98.5 \%$ accuracy the presence of fibrosis. However, the negative predictive value of only $75 \%$ for a cutoff $<3.47$ suggested the use of caution in ruling out fibrosis based on this scoring system [49]. This issue was addressed two years later, by Alkhouri et al., in a prospective study including 111 patients diagnosed with NAFLD. The authors assessed the fibrosis prediction accuracy of ELF score, PNFI, and a combination of the two, when compared to LB. The results for the combined use of these scores showed a significant improvement of the estimated hepatic fibrosis, especially for the patients falling between the two cutoff values of PNFI, for which an ELF score of over 8.49 indicated a high risk of fibrosis [43].

\section{Imagistic evaluation}

\section{Evaluation of steatosis}

To date, abdominal US is the most frequently utilized imagistic method for the evaluation of NAFLD [50]. This is due to its numerous advantages, such as relatively low cost, lack of invasiveness, high availability, and high rate of acceptance by the patient [50]. Steatosis is easily recognized by the experienced user presenting as high hepatic echogenicity, visualization of hepatic vessels, low diaphragm visualization, and posterior attenuation [51, 52]. However, despite its many advantages, US presents high levels of interobserver and intraobserver variability and thus the results need to be interpreted with caution [53]. Although the overall accuracy of US for the detection of NAFLD is relatively high in the adult population [54], the results are not as satisfactory in pediatric patients because of its low specificity and sensitivity [55], thus US is not currently recommended for the screening of NAFLD by NASPGHAN. However, this inexpensive imagistic method could be used especially to exclude other possible liver disease such as hepatic masses, gallbladder disease, or portal hypertension [38].

Computed tomography (CT) examination is more reliable than US in the evaluation of NAFLD and presents good accuracy for the detection of steatosis. Hepatic steatosis is diagnosed in the presence of a difference between the hepatic and splenic attenuation index of less than 25 Hounsfield units (HU) [56]. Its use is however limited because of the radiation risk and thus it is not recommended as an initial evaluation by the NASPGHAN [57]. However, although CT examination is not routinely used for the detection of steatosis, when performed for alternative indications it shows a good accuracy for predicting steatosis, with a sensitivity of 46-72\% and specificity 88-95\% [34].

Magnetic resonance (MR) studies are generally considered too expensive for routine clinical practice [34] but provide a good accuracy for the detection and quantification of steatosis by differentiating the tissues that contain water from those containing both fat and water [58]. MR imaging (MRI) has shown good sensitivity and specificity for the detection and quantification of steatosis, and thus, novel approaches have been developed to improve the accuracy of this imaging method. Proton MR spectroscopy $\left({ }^{1} \mathrm{H}-\mathrm{MRS}\right)$ has been found to be accurate in the assessment of steatosis both in adult and in pediatric patients [59]. ${ }^{1} \mathrm{H}-\mathrm{MRS}$ has proven to be particularly useful in detecting even low-grade steatosis, when the percent of hepatic fat accumulation is less than 30\% [57]. MR-proton density fat fraction (PDFF) was recently validated as an accurate method for the assessment of steatosis. MR-PDFF was found to have a good accuracy in differentiating between grade 1 versus grade 2-3 steatosis (AUC=0.87) [36], as well as discriminating between grade 0 and 1 steatosis, with an AUC of 0.82 [60], thus representing a potential candidate for LB replacement. However, the issue of cost-efficiency remains to be further evaluated.

\section{Evaluation of fibrosis}

Transient elastography (TE) has proved to be a reliable non-invasive method for the quantification of liver fibrosis in adult patients and has shown promising results in patients with viral hepatitis [61], as well as in NAFLD, especially when used for the staging of high fibrosis [62, 63]. However, there were not many studies evaluating the accuracy of TE in pediatric patients. Nobili et al., in a prospective study carried out in 2008 that included 52 patients with biopsy-proven NASH, found TE to be an adequate predictor for advanced but not for intermediate fibrosis [63]. In 2013, Alkhouri et al. studied the prediction accuracy for fibrosis of TE and PNFI in a cohort of 67 pediatric patients diagnosed with NAFLD. The results indicated that the combination of TE and PNFI could predict the presence or absence of significant fibrosis with 98\% accuracy [64]. A more recent review and metaanalysis comprising a total sample size of 723 pediatric patients hospitalized for various chronic liver diseases found that TE presented a high accuracy for the detection of significant fibrosis, with a sensitivity and specificity of $95 \%$ and $90 \%$, respectively [65]. However, as most of the studies included in the analysis included an inhomogeneous population that associated multiple etiologies of liver disease the conclusions could not be applied for patients with NAFLD.

Several other non-invasive imagistic techniques, such as US elastography, but also contrast-enhanced US previously validated in adult patients have been studied in children with promising results, but data comprising large homogenous groups of NAFLD patients are not available [52]. Acoustic radiation force impulse (ARFI) is a non-invasive technique integrated into an US machine that uses sound waves to induce shear waves that propagate along the US beam. The method has been validated in adult NAFLD patients and results are promising in pediatric patients as well [66]. Although sample size was generally small in pediatric studies $[67,68]$ and some authors included patients with diverse liver disease etiologies $[69,70]$ the results indicated that ARFI could represent an adequate predictor of hepatic fibrosis [71]. 
MR elastography (MRE) is a novel noninvasive method of evaluation of liver fibrosis in NAFLD pediatric patients which focuses on phase-contrast sequence as a method of observing the propagation of share-waves. Although it has been proven to be useful in predicting hepatic fibrosis in adult patients [72], not many studies have evaluated its role in children and the results, although promising, are inhomogeneous. Thus, certain authors reported various accuracy levels of MRE depending on the evaluated fibrosis stage of NAFLD patients, varying from an AUC of 0.53 to 0.77 for the prediction of stage 1 fibrosis $[59,72]$ to an AUC of 0.93 for stage 3 fibrosis [60]. However, the implementation of this method in current clinical practice requires more in-depth as well as cost-efficiency studies; the need of sedation for pediatric patients could represent a disadvantage [34].

Shear wave elastography (SWE) is a recently introduced US-derived method for the evaluation of hepatic fibrosis in adult patients that could also be useful in pediatric patients. The principle of the method resides in the generation and propagation of high frequency US providing real time information concerning the velocity of shear wave propagation, thus estimating liver fibrosis [71]. Tutar et al. have evaluated SWE in a study including 76 children with chronic liver disease and compared them with 50 healthy subjects. Their results indicated that SWE presented a good accuracy for diagnosing liver fibrosis, with $91.5 \%$ sensitivity and $94.0 \%$ specificity [71]. Although SWE presents potential for applicability in pediatric patients, large prospective studies are needed in order to compare the accuracy of this method to that of LB [73].

\section{口 Conclusions}

Important progress has been made in creating noninvasive methods to efficiently identify liver disease in children who suffer of NAFLD. Whereas conventional US could be used as triage in large, unselected populations, MRI is the most accurate method for detection and grading of steatosis. Concerning steatohepatitis, it was found that neither imaging modality nor blood tests are not highly sensitive for the NAFLD diagnosis. LB remains the "gold standard" in identifying inflammation and fibrosis. However, increasing proof indicates that serum markers and liver stiffness have the capacity to reveal which subgroup of patients with NAFLD is at a higher risk of developing further complications. Given the fact that well established radiological and HP diagnostic tests are absent, it is the multidisciplinary team members' high clinical suspicion which serves as the strongest diagnostic tool.

\section{Conflict of interest}

The authors declare that they have no conflict of interests.

\section{Authors' contribution}

Laura Mihaela Trandafir and Otilia Elena Frasinariu equally contributed to the manuscript.

\section{References}

[1] Flisiak-Jackiewicz M, Lebensztejn DM. Update on pathogenesis, diagnostics and therapy of nonalcoholic fatty liver disease in children. Clin Exp Hepatol, 2019, 5(1):11-21. https://doi.org/ 10.5114/ceh.2019.83152 PMID: 30915402 PMCID: PMC 6431091
[2] Goldner D, Lavine JE. Nonalcoholic fatty liver disease in children: unique considerations and challenges. Gastroenterology, 2020, 158(7):1967-1983.e1. https://doi.org/10. 1053/j.gastro.2020.01.048 PMID: 32201176

[3] Feldstein AE, Charatcharoenwitthaya P, Treeprasertsuk S, Benson JT, Enders FB, Angulo P. The natural history of nonalcoholic fatty liver disease in children: a follow-up study for up to 20 years. Gut, 2009, 58(11):1538-1544. https://doi.org/ 10.1136/gut.2008.171280 PMID: 19625277 PMCID: PMC 2792743

[4] Paschos P, Paletas K. Non alcoholic fatty liver disease and metabolic syndrome. Hippokratia, 2009, 13(1):9-19. PMID: 19240815 PMCID: PMC2633261

[5] Anderson EL, Howe LD, Jones HE, Higgins JPT, Lawlor DA, Fraser A. The prevalence of non-alcoholic fatty liver disease in children and adolescents: a systematic review and metaanalysis. PLoS One, 2015, 10(10):e0140908. https://doi.org/ 10.1371/journal.pone.0140908 PMID: 26512983 PMCID: PMC4626023

[6] Schwimmer JB, Deutsch R, Kahen T, Lavine JE, Stanley C, Behling $\mathrm{C}$. Prevalence of fatty liver in children and adolescents. Pediatrics, 2006, 118(4):1388-1393. https://doi.org/10.1542/ peds.2006-1212 PMID: 17015527

[7] Wong T, Wong RJ, Gish RG. Diagnostic and treatment implications of nonalcoholic fatty liver disease and nonalcoholic steatohepatitis. Gastroenterol Hepatol (N Y). 2019, 15(2):8389. PMID: 31011302 PMCID: PMC6469262

[8] Boyraz M, Hatipoğlu N, Sarı E, Akçay A, Taşkın N, Ulucan K, Akçay T. Non-alcoholic fatty liver disease in obese children and the relationship between metabolic syndrome criteria. Obes Res Clin Pract, 2014, 8(4):e356-e363. https://doi.org/ 10.1016/j.orcp.2013.08.003 PMID: 25091357

[9] Clemente MG, Mandato C, Poeta M, Vajro P. Pediatric nonalcoholic fatty liver disease: recent solutions, unresolved issues, and future research directions. World J Gastroenterol, 2016, 22(36):8078-8093. https://doi.org/10.3748/wjg.v22.i36.8078 PMID: 27688650 PMCID: PMC5037077

[10] Fang $Y L$, Chen $H$, Wang $C L$, Liang L. Pathogenesis of nonalcoholic fatty liver disease in children and adolescence: from "two hit theory" to "multiple hit model". World J Gastroenterol, 2018, 24(27):2974-2983. https://doi.org/10.3748/wjg.v24.i27. 2974 PMID: 30038464 PMCID: PMC6054950

[11] Angulo $P$. Obesity and nonalcoholic fatty liver disease. Nutr Rev, 2007, 65(6 Pt 2):S57-S63. https://doi.org/10.1111/j.17 53-4887.2007.tb00329.x PMID: 17605315

[12] Nobili V, Socha P. Pediatric nonalcoholic fatty liver disease: current thinking. J Pediatr Gastroenterol Nutr, 2018, 66(2): 188-192. https://doi.org/10.1097/MPG.0000000000001823 PMID: 29356764

[13] Theise ND. Liver and gallbladder. In: Kumar V, Abbas AK, Aster JC (eds). Robbins and Cotran pathologic basis of disease professional edition (Robbins pathology). $9^{\text {th }}$ edition, ElsevierSaunders, 2015, 821-882. https://www.elsevier.com/books/ robbins-and-cotran-pathologic-basis-of-disease/kumar/978-14557-2613-4

[14] Nakanishi Y, Saxena R. Nonneoplastic hepatobiliary disease. In: Cheng L, Bostwick DG (eds). Essentials of anatomic pathology. $4^{\text {th }}$ edition, Springer, Cham, 2016, 1969-2030. https://doi.org/10.1007/978-3-319-23380-2_44

[15] Eder SK, Feldman A, Strebinger G, Kemnitz J, Zandanell S, Niederseer D, Strasser M, Haufe H, Sotlar K, Stickel F, Paulweber B, Datz C, Aigner E. Mesenchymal iron deposition is associated with adverse long-term outcome in non-alcoholic fatty liver disease. Liver Int, 2020, 40(8):1872-1882. https:// doi.org/10.1111/liv.14503 PMID: 32378295 PMCID: PMC 7496452

[16] Braun HA, Faasse SA, Vos MB. Advances in pediatric fatty liver disease: pathogenesis, diagnosis, and treatment. Gastroenterol Clin North Am, 2018, 47(4):949-968. https://doi.org/ 10.1016/j.gtc.2018.07.016 PMID: 30337043

[17] Crespo M, Lappe S, Feldstein AE, Alkhouri N. Similarities and differences between pediatric and adult nonalcoholic fatty liver disease. Metabolism, 2016, 65(8):1161-1171. https:// doi.org/10.1016/j.metabol.2016.01.008 PMID: 26961580

[18] Takahashi Y, Fukusato T. Histopathology of nonalcoholic fatty liver disease/nonalcoholic steatohepatitis. World J Gastroenterol, 2014, 20(42):15539-15548. https://doi.org/10.3748/ wjg.v20.i42.15539 PMID: 25400438 PMCID: PMC4229519 
[19] Bush H, Golabi P, Younossi ZM. Pediatric non-alcoholic fatty liver disease. Children (Basel), 2017, 4(6):48. https://doi.org/ 10.3390/children4060048 PMID: 28598410 PMCID: PMC 5483623

[20] Alfani R, Vassallo E, De Anseris AG, Nazzaro L, D'Acunzo I, Porfito C, Mandato C, Vajro P. Pediatric fatty liver and obesity: not always just a matter of non-alcoholic fatty liver disease. Children (Basel), 2018, 5(12):169. https://doi.org/10.3390/ children5120169 PMID: 30551665 PMCID: PMC6306738

[21] Mani H, Stocker JT. Liver, biliary tract, and pancreas. In: Husain AN, Stocker JT (eds). Color atlas of pediatric pathology. Demos Medical Publishing, New York, 2011, 265-318.

[22] Nalbantoglu ILK, Brunt EM. Role of liver biopsy in nonalcoholic fatty liver disease. World J Gastroenterol, 2014 20(27):9026-9037. https://doi.org/10.3748/wjg.v20.i27.9026 PMID: 25083076 PMCID: PMC4112884

[23] Kleiner DE, Makhlouf HR. Histology of nonalcoholic fatty liver disease and nonalcoholic steatohepatitis in adults and children. Clin Liver Dis, 2016, 20(2):293-312. https://doi.org/ 10.1016/j.cld.2015.10.011 PMID: 27063270 PMCID: PMC 4829204

[24] Schwarz JM, Noworolski SM, Erkin-Cakmak A, Korn NJ, Wen MJ, Tai VW, Jones GM, Palii SP, Velasco-Alin M, Pan K, Patterson BW, Gugliucci A, Lustig RH, Mulligan K. Effects of dietary fructose restriction on liver fat, de novo lipogenesis, and insulin kinetics in children with obesity. Gastroenterology, 2017, 153(3):743-752. https://doi.org/10.1053/j.gastro.2017. 05.043 PMID: 28579536 PMCID: PMC5813289

[25] Kleiner DE. Histopathology, grading and staging of nonalcoholic fatty liver disease. Minerva Gastroenterol Dietol, 2018, 64(1):28-38. https://doi.org/10.23736/S1121-421X.17. 02445-X PMID: 28948754

[26] Brunt EM, Janney CG, Di Bisceglie AM, NeuschwanderTetri BA, Bacon BR. Nonalcoholic steatohepatitis: a proposal for grading and staging the histological lesions. Am J Gastroenterol, 1999, 94(9):2467-2474. https://doi.org/10.1111/j.15 72-0241.1999.01377.x PMID: 10484010

[27] Kleiner DE, Brunt EM, Van Natta M, Behling C, Contos MJ, Cummings OW, Ferrell LD, Liu YC, Torbenson MS, UnalpArida A, Yeh M, McCullough AJ, Sanyal AJ; Nonalcoholic Steatohepatitis Clinical Research Network. Design and validation of a histological scoring system for nonalcoholic fatty liver disease. Hepatology, 2005, 41(6):1313-1321. https:// doi.org/10.1002/hep.20701 PMID: 15915461

[28] Bedossa P, Poitou C, Veyrie N, Bouillot JL, Basdevant A, Paradis V, Tordjman J, Clement K. Histopathological algorithm and scoring system for evaluation of liver lesions in morbidly obese patients. Hepatology, 2012, 56(5):1751-1759. https:// doi.org/10.1002/hep.25889 PMID: 22707395

29] Draijer L, Benninga M, Koot B. Pediatric NAFLD: an overview and recent developments in diagnostics and treatment. Expert Rev Gastroenterol Hepatol, 2019, 13(5):447-461. https:// doi.org/10.1080/17474124.2019.1595589 PMID: 30875479

[30] Rinella ME. Nonalcoholic fatty liver disease: a systematic review. JAMA, 2015, 313(22):2263-2273. https://doi.org/10. 1001/jama.2015.5370. Erratum in: JAMA, 2015, 314(14):1521. PMID: 26057287

[31] Zhou JH, Cai JJ, She ZG, Li HL. Noninvasive evaluation of nonalcoholic fatty liver disease: current evidence and practice. World J Gastroenterol, 2019, 25(11):1307-1326. https://doi.org/ 10.3748/wjg.v25.i11.1307 PMID: 30918425 PMCID: PMC 6429343

[32] Brunt EM. Pathology of nonalcoholic fatty liver disease. Nat Rev Gastroenterol Hepatol, 2010, 7(4):195-203. http://doi.org/ 10.1038/nrgastro.2010.21 PMID: 20195271

[33] Straub BK, Schirmacher P. Pathology and biopsy assessment of non-alcoholic fatty liver disease. Dig Dis, 2010, 28(1):197202. http://doi.org/10.1159/000282086 PMID: 20460911

[34] Vos MB, Abrams SH, Barlow SE, Caprio S, Daniels SR, Kohli R, Mouzaki M, Sathya P, Schwimmer JB, Sundaram SS, Xanthakos SA. NASPGHAN Clinical Practice Guideline for the Diagnosis and Treatment of Nonalcoholic Fatty Liver Disease in Children: Recommendations from the Expert Committee on NAFLD (ECON) and the North American Society of Pediatric Gastroenterology, Hepatology and Nutrition (NASPGHAN). J Pediatr Gastroenterol Nutr, 2017, 62(2):319-334. https:// doi.org/10.1097/MPG.0000000000001482 PMID: 28107283 PMCID: PMC5413933
[35] Robertson G, Leclercq I, Farrell GC. Nonalcoholic steatosis and steatohepatitis. II. Cytochrome P-450 enzymes and oxidative stress. Am J Physiol Gastrointest Liver Physiol, 2001, 281(5):G1135-G1139. http://doi.org/10.1152/ajpgi.2001. 281.5.G1135 PMID: 11668021

[36] Honar N, Jooya P, Haghighat M, Imanieh MH, Dehghani SM, Zahmatkeshan M, Javaherizadeh H. Complications of blind versus ultrasound-guided percutaneous liver biopsy in children. Arab J Gastroenterol, 2015, 16(3-4):90-93. https://doi.org/ 10.1016/j.ajg.2015.09.009 PMID: 26526508

[37] Nobili V, Parkes J, Bottazzo G, Marcellini M, Cross R, Newman D, Vizzutti F, Pinzani M, Rosenberg WM. Performance of ELF serum markers in predicting fibrosis stage in pediatric non-alcoholic fatty liver disease. Gastroenterology, 2009, 136(1):160-167. https://doi.org/10.1053/j.gastro.2008.09.013 PMID: 18992746

[38] Mohamed AA, Sabry S, Abdallah AM, Elazeem NAA, Refaey D, Algebaly HAF, Fath GAE, Omar H. Circulating adipokines in children with nonalcoholic fatty liver disease: possible noninvasive diagnostic markers. Ann Gastroenterol, 2017, 30(4):457-463. https://doi.org/10.20524/aog.2017.0148 PMID: 28655985 PMCID: PMC5480001

[39] Lebensztejn DM, Wojtkowska M, Skiba E, Werpachowska I, Tobolczyk J, Kaczmarski M. Serum concentration of adiponectin, leptin and resistin in obese children with non-alcoholic fatty liver disease. Adv Med Sci, 2009, 54(2):177-182. https://doi. org/10.2478/v10039-009-0047-y PMID: 20022856

[40] Drescher HK, Weiskirchen S, Weiskirchen R. Current status in testing for nonalcoholic fatty liver disease (NAFLD) and nonalcoholic steatohepatitis (NASH). Cells, 2019, 8(8):845. https://doi.org/10.3390/cells8080845 PMID: 31394730 PMCID: PMC6721710

[41] Chalasani N, Younossi Z, Lavine JE, Charlton M, Cusi K, Rinella M, Harrison SA, Brunt EM, Sanyal AJ. The diagnosis and management of nonalcoholic fatty liver disease: practice guidance from the American Association for the Study of Liver Diseases. Hepatology, 2018, 67(1):328-357. https:// doi.org/10.1002/hep.29367 PMID: 28714183

[42] Church RJ, Watkins PB. The transformation in biomarker detection and management of drug-induced liver injury. Liver Int, 2017, 37(11):1582-1590. https://doi.org/10.1111/liv.13441 PMID: 28386997 PMCID: PMC5632128

[43] Alkhouri N, Carter-Kent C, Lopez R, Rosenberg WM, Pinzani M, Bedogni G, Feldstein AE, Nobili V. A combination of the pediatric NAFLD fibrosis index and enhanced liver fibrosis test identifies children with fibrosis. Clin Gastroenterol Hepatol, 2011, 9(2):150-155. https://doi.org/10.1016/j.cgh.2010.09.015 PMID: 20888433

[44] Shah AG, Lydecker A, Murray K, Tetri BN, Contos MJ, Sanyal AJ; Nash Clinical Research Network. Comparison of noninvasive markers of fibrosis in patients with nonalcoholic fatty liver disease. Clin Gastroenterol Hepatol, 2009, 7(10): 1104-1112. https://doi.org/10.1016/j.cgh.2009.05.033 PMID: 19523535 PMCID: PMC3079239

[45] Patton HM, Lavine JE, Van Natta ML, Schwimmer JB Kleiner D, Molleston J; Nonalcoholic Steatohepatitis Clinical Research Network. Clinical correlates of histopathology in pediatric nonalcoholic steatohepatitis. Gastroenterology, 2008 135(6):1961-1971.e2. https://doi.org/10.1053/j.gastro.2008. 08.050 PMID: 19013463 PMCID: PMC2628583

[46] Mansoor S, Yerian L, Kohli R, Xanthakos S, Angulo P, Ling S, Lopez R, Christine CK, Feldstein AE, Alkhouri N. The evaluation of hepatic fibrosis scores in children with nonalcoholic fatty liver disease. Dig Dis Sci, 2015, 60(5):1440-1447. https:// doi.org/10.1007/s10620-014-3494-7 PMID: 25540086

[47] Leung DH. Hepatic fibrosis scores and serum biomarkers in pediatric hepatology. Clin Liver Dis (Hoboken), 2017, 9(5): 125-130. https://doi.org/10.1002/cld.634 PMID: 30992975 PMCID: PMC6467157

[48] Yang HR, Kim HR, Kim MJ, Ko JS, Seo JK. Noninvasive parameters and hepatic fibrosis scores in children with nonalcoholic fatty liver disease. World J Gastroenterol, 2012, 18(13):1525-1530. https://doi.org/10.3748/wjg.v18.i13.1525 PMID: 22509085 PMCID: PMC3319949

[49] Nobili V, Alisi A, Vania A, Tiribelli C, Pietrobattista A, Bedogni G. The pediatric NAFLD fibrosis index: a predictor of liver fibrosis in children with non-alcoholic fatty liver disease. BMC Med, 2009, 7:21. https://doi.org/10.1186/1741-7015-7-21 PMID: 19409076 PMCID: PMC2684116 
[50] Ozturk A, Grajo JR, Gee MS, Benjamin A, Zubajlo RE, Thomenius KE, Anthony BW, Samir AE, Dhyani M. Quantitative hepatic fat quantification in non-alcoholic fatty liver disease using ultrasound-based techniques: a review of literature and their diagnostic performance. Ultrasound Med Biol, 2018, 44(12):2461-2475. https://doi.org/10.1016/j.ultrasmedbio.2018. 07.019 PMID: 30232020 PMCID: PMC6628698

[51] Nobili V, Alisi A, Valenti L, Miele L, Feldstein AE, Alkhouri N. NAFLD in children: new genes, new diagnostic modalities and new drugs. Nat Rev Gastroenterol Hepatol, 2019, 16(9): 517-530. https://doi.org/10.1038/s41575-019-0169-z PMID: 31278377

[52] Yoon H, Shin HJ, Kim MJ, Lee MJ. Quantitative imaging in pediatric hepatobiliary disease. Korean J Radiol, 2019, 20(9):1342-1357. https://doi.org/10.3348/kjr.2019.0002 PMID: 31464113 PMCID: PMC6715564

[53] Cengiz M, Sentürk S, Cetin B, Bayrak AH, Bilek SU. Sonographic assessment of fatty liver: intraobserver and interobserver variability. Int J Clin Exp Med, 2014, 7(12): 5453-5460. PMID: 25664055 PMCID: PMC4307502

[54] Hernaez R, Lazo M, Bonekamp S, Kamel I, Brancati FL, Guallar E, Clark JM. Diagnostic accuracy and reliability of ultrasonography for the detection of fatty liver: a meta-analysis. Hepatology, 2011, 54(3):1082-1090. https://doi.org/10.1002/ hep.24452 PMID: 21618575 PMCID: PMC4197002

[55] Awai HI, Newton KP, Sirlin CB, Behling C, Schwimmer JB. Evidence and recommendations for imaging liver fat in children, based on systematic review. Clin Gastroenterol Hepatol, 2014, 12(5):765-773. https://doi.org/10.1016/j.cgh.2013.09. 050 PMID: 24090729 PMCID: PMC3969892

[56] Dhaliwal J, Chavhan GB, Lurz E, Shalabi A, Yuen N, Williams B, Martincevic I, Amirabadi A, Wales PW, Lee W, Ling SC, Mouzaki M. Hepatic steatosis is highly prevalent across the paediatric age spectrum, including in pre-school age children. Aliment Pharmacol Ther, 2018, 48(5):556-563. https://doi.org/10.1111/apt.14900 PMID: 29998462

[57] Bohte AE, van Werven JR, Bipat S, Stoker J. The diagnostic accuracy of US, CT, MRI and ${ }^{1} \mathrm{H}-\mathrm{MRS}$ for the evaluation of hepatic steatosis compared with liver biopsy: a meta-analysis. Eur Radiol, 2011, 21(1):87-97. https://doi.org/10.1007/s003 30-010-1905-5 PMID: 20680289 PMCID: PMC2995875

[58] Middleton MS, Van Natta ML, Heba ER, Alazraki A, Trout AT, Masand P, Brunt EM, Kleiner DE, Doo E, Tonascia J, Lavine JE, Shen W, Hamilton G, Schwimmer JB, Sirlin CB; NASH Clinical Research Network. Diagnostic accuracy of magnetic resonance imaging hepatic proton density fat fraction in pediatric nonalcoholic fatty liver disease. Hepatology, 2018 67(3):858-872. https://doi.org/10.1002/hep.29596 PMID: 29028128 PMCID: PMC6211296

[59] Schwimmer JB, Middleton MS, Behling C, Newton KP, Awai HI, Paiz MN, Lam J, Hooker JC, Hamilton G, Fontanesi J, Sirlin CB. Magnetic resonance imaging and liver histology as biomarkers of hepatic steatosis in children with nonalcoholic fatty liver disease. Hepatology, 2015, 61(6):1887-1895. https://doi.org/ 10.1002/hep.27666 PMID: 25529941 PMCID: PMC4670559

[60] Schwimmer JB, Behling C, Angeles JE, Paiz M, Durelle J, Africa J, Newton KP, Brunt EM, Lavine JE, Abrams SH, Masand P, Krishnamurthy R, Wong K, Ehman RL, Yin M, Glaser KJ, Dzyubak B, Wolfson T, Gamst AC, Hooker J, Haufe W, Schlein A, Hamilton G, Middleton MS, Sirlin CB. Magnetic resonance elastography measured shear stiffness as a biomarker of fibrosis in pediatric nonalcoholic fatty liver disease. Hepatology, 2017, 66(5):1474-1485. https://doi.org/ 10.1002/hep.29241 PMID: 28493388 PMCID: PMC5650504

[61] Trifan A, Stanciu C. Checkmate to liver biopsy in chronic hepatitis C? World J Gastroenterol, 2012, 18(39):5514-5520. https://doi.org/10.3748/wjg.v18.i39.5514 PMID: 23112543 PMCID: PMC3482637
[62] Tsai E, Lee TP. Diagnosis and evaluation of nonalcoholic fatty liver disease/nonalcoholic steatohepatitis, including noninvasive biomarkers and transient elastography. Clin Liver Dis, 2018, 22(1):73-92. https://doi.org/10.1016/j.cld.2017.08.004 PMID: 29128062

[63] Nobili V, Vizzutti F, Arena U, Abraldes JG, Marra F, Pietrobattista A, Fruhwirth R, Marcellini M, Pinzani M. Accuracy and reproducibility of transient elastography for the diagnosis of fibrosis in pediatric nonalcoholic steatohepatitis. Hepatology, 2008, 48(2):442-448. https://doi.org/10.1002/hep.22376 PMID: 18563842

[64] Alkhouri N, Sedki E, Alisi A, Lopez R, Pinzani M, Feldstein AE, Nobili V. Combined paediatric NAFLD fibrosis index and transient elastography to predict clinically significant fibrosis in children with fatty liver disease. Liver Int, 2013, 33(1):7985. https://doi.org/10.1111/liv.12024 PMID: 23146095

[65] Hwang JY, Yoon HM, Kim JR, Lee JS, Jung AY, Kim KM, Cho YA. Diagnostic performance of transient elastography for liver fibrosis in children: a systematic review and metaanalysis. AJR Am J Roentgenol, 2018, 211(5):W257-W266. https://doi.org/10.2214/AJR.18.19535 PMID: 30106615

[66] Berná-Serna JD, Sánchez-Jiménez R, Velázquez-Marín F, Sainz de Baranda P, Guzmán-Aroca F, Fernández-Hernández C, Doménech-Abellán $E$, Abellán-Rivero $D$, Ruiz-Merino $G$, Madrid-Conesa J, Canteras-Jordana M. Acoustic radiation force impulse imaging for detection of liver fibrosis in overweight and obese children. Acta Radiol, 2018, 59(2):247-253. https:// doi.org/10.1177/0284185117707359 PMID: 28475023

[67] Hanquinet S, Rougemont AL, Courvoisier D, Rubbia-Brandt L, McLin V, Tempia M, Anooshiravani M. Acoustic radiation force impulse (ARFI) elastography for the noninvasive diagnosis of liver fibrosis in children. Pediatr Radiol, 2013, 43(5):545551. https://doi.org/10.1007/s00247-012-2595-8 PMID: 23271404

[68] Noruegas MJ, Matos H, Gonçalves I, Cipriano MA, Sanches C. Acoustic radiation force impulse-imaging in the assessment of liver fibrosis in children. Pediatr Radiol, 2012, 42(2):201204. https://doi.org/10.1007/s00247-011-2257-2 PMID: 22002843

[69] Sagir A, Ney D, Oh J, Pandey S, Kircheis G, Mayatepek E, Häussinger D. Evaluation of acoustic radiation force impulse imaging (ARFI) for the determination of liver stiffness using transient elastography as a reference in children. Ultrasound Int Open, 2015, 1(1):E2-E7. https://doi.org/10.1055/s-00351554659 PMID: 27689145 PMCID: PMC5023198

[70] Mandelia C, Kabbany MN, Conjeevaram Selvakumar PK, Alkhouri N. The search for noninvasive methods to identify liver fibrosis in children with nonalcoholic fatty liver disease. Biomark Med, 2018, 12(3):265-273. https://doi.org/10.2217/ bmm-2017-0038 PMID: 29517271

[71] Cui J, Ang B, Haufe W, Hernandez C, Verna EC, Sirlin CB, Loomba R. Comparative diagnostic accuracy of magnetic resonance elastography $v s$. eight clinical prediction rules for non-invasive diagnosis of advanced fibrosis in biopsy-proven non-alcoholic fatty liver disease: a prospective study. Aliment Pharmacol Ther, 2015, 41(12):1271-1280. https://doi.org/10. 1111/apt.13196 PMID: 25873207 PMCID: PMC4532628

[72] Trout AT, Sheridan RM, Serai SD, Xanthakos SA, Su W, Zhang B, Wallihan DB. Diagnostic performance of MR elastography for liver fibrosis in children and young adults with a spectrum of liver diseases. Radiology, 2018, 287(3): 824-832. https://doi.org/10.1148/radiol.2018172099 PMID: 29470938

[73] Tutar O, Beser ÖF, Adaletli I, Tunc N, Gulcu D, Kantarci F, Mihmanli I, Cokugras FC, Kutlu T, Ozbay G, Erkan T. Shear wave elastography in the evaluation of liver fibrosis in children. J Pediatr Gastroenterol Nutr, 2014, 58(6):750-755. https:// doi.org/10.1097/MPG.0000000000000329 PMID: 24552673

\section{Corresponding authors}

Maria Magdalena Leon-Constantin, Associate Professor, MD, PhD, First Medical Department, Grigore T. Popa University of Medicine and Pharmacy, 16 University Street, 700115 laşi, Romania; Phone +40232-301 600, e-mail: leon_mariamagdalena@yahoo.com

Ştefan Chiriac, Assistant Professor, MD, PhD, First Medical Department, Grigore T. Popa University of Medicine and Pharmacy, 16 University Street, 700115 laşi, Romania; Phone +40232-301 600, e-mail: stefannchiriac@yahoo.com 